\title{
Prevalensi dan Hubungan Higiene Sanitasi Terhadap Kontaminasi Telur STH pada Sayur Kemangi (Ocimum basilicum L.) yang dijual sebagai Hidangan Lalapan di Kecamatan Semarang Barat
}

\author{
Benaya Yamin Onesiforus ${ }^{1}$, Rizka Anindya Priaryuningtyas ${ }^{2}$, Reswari Galuh ${ }^{3}$ \\ 1,2,3 Program Studi DIII Analis Kesehatan, Politeknik Katolik Mangunwijaya, Indonesia
}

\begin{abstract}
Article Info
Article history:

Received Feb 24 $4^{\text {th }}, 2021$

Revised Aug 27 2021

Accepted Sep 06 ${ }^{\text {th }}, 2021$
\end{abstract}

\section{Keyword:}

Basil leaves,

Hygiene sanitation,

STH contamination,

West Semarang

\begin{abstract}
Lalapan are raw vegetables which are commonly consumed among Indonesian people, especially in Java Island. Basil leaves (Ocimum basilicum L.) are the most common lalapan in Indonesia. This research objeticves was to determine the prevalence and influence of hygiene sanitation on Soil Transmitted Helminths (STH) eggs contamination on basil leaves sold as lalapan in West Semarang District. This study was conducted in descriptive and experimental study. Descriptive study was a cross-sectional study on 40 fried chicken street vendors who sold basil as lalapan in West Semarang District. The examination was carried out using the sedimentation method. Experimental study was conducted on basil samples with 4 treatment: control, stagnant water washing, running water washing, and washing with vegetable washing liquid. Result showed STH contamination prevalence of 25\% on basil leaves. Ordinal Regression Test result showed that habit of washing vegetables and water resources did not have a significant effect $(\mathrm{p}>0.05)$, while hand washing habit showed a significant effect $(\mathrm{p}<0.05)$ to STH contamination on basil leaves. Chi-square test showed that stagnant water and running water washing treatment did not show a significant difference. Washing with vegetable washing liquid could remove $100 \%$ of STH eggs contamination on basil leaves. Street vendors are suggest to wash their basil leaves with vegetable washing liquid in order to minimize risk of STH infection to consumers.
\end{abstract}

\begin{abstract}
ABSTRAK
Sayur lalapan merupakan makanan pendamping yang umum dikonsumsi oleh masyarakat Indonesia, khususnya yang berada di Pulau Jawa. Salah satu jenis sayuran yang umum dikonsumsi sebagai lalapan adalah kemangi (Ocimum basilicum L.). Sayur lalapan dapat berperan sebagai sumber infeksi Soil Transmitted Helminth (STH) karena dikonsumsi dalam keadaan mentah. Tujuan dari penelitian ini adalah mengetahui prevalensi dan pengaruh hygiene sanitasi terhadap kontaminasi STH pada daun kemangi yang dijual sebagai lalapan di Kecamatan Semarang Barat. Peneltian dilakukan secara deskriptif dan eksperimental. Penelitian deskriptif merupakan penelitian cross-sectional pada 40 pedagang kaki lima (PKL) ayam goreng yang menggunakan kemangi sebagai lalapan di Kecamatan Semarang Barat. Pemeriksaan dilakukan dengan menggunakan metode sedimentasi. Penelitian eksperimental dilakukan pada sampel kemangi dengan 4 perlakuan: control, pencucian air terendam, pencucian air mengalir, dan pencucian dengan sabun pencuci sayuran. Hasil penelitian menunjukkan terdapat prevalensi kontaminasi STH sebesar 25\% pada lalapan kemangi di Semarang Barat. Hasil uji Regresi Ordinal menunjukkan kebiasaan mencuci sayuran dan sumber air tidak menunjukkan pengaruh signifikan $(\mathrm{p}>0,05)$, sementara perilaku mencuci tangan menunjukkan pengaruh signifikan $(\mathrm{p}<0,05)$ terhadap kontaminasi STH pada lalapan kemangi. Uji chi-square menunjukkan perlakuan pencucian air terendam dan air mengalir tidak menunjukkan perbedaan signifikan. Pencucian
\end{abstract}


dengan sabun sayur dapat menghilangkan $100 \%$ kontaminasi telur STH pada kemangi. PKL sebaiknya melakukan pencucian kemangi dengan air sabun untuk menurunkan resiko infeksi STH pada para konsumen.

Kata Kunci : Kemangi, higiene sanitasi, kontaminasi STH, Semarang Barat

\section{Pendahuluan}

Sayuran merupakan bahan makanan pokok yang kaya gizi dan banyak dikonsumsi oleh kebanyakan masyarakat Indonesia. Masyarakat Indonesia menggunakan sayuran sebagai makanan pokok maupun makanan pendamping. Sebelum dikonsumsi, umumnya sayuran akan dicuci terlebih dahulu untuk kemudian dimasak. Tujuan dari pencucian adalah untuk menghilang berbagai kotoran, sisa zat pestisida, serta parasit yang mungkin terdapat di sayuran, kemudian dimasak. Selain sebagai makanan pokok, masyarakat Indonesia juga mengenal sayuran lalapan, yakni sayuran yang dikonsumsi secara mentah sebagai makanan pendamping (Widjaja et. al., 2014). Kebiasaan mengkonsumsi lalapan ini tersebar di seluruh Indonesia, namun paling banyak ditemukan di Pulau Jawa. Tiap daerah dapat memiliki jenis sayur masing-masing yang digunakan sebagai lalapan. Beberapa jenis sayuran yang umum digunakan sebagai lalapan antara lain: daun kubis (Brassica oleracea), kemangi $(O$. basilicum L.), daun singkong (Manihot esculenta) dan mentimun (Cucumis sativus L.). Kemangi merupakan salah satu jenis sayuran yang paling umum dikonsumsi oleh masyarakat Indonesia di Pulau Jawa.

Sayuran mentah, khususnya lalapan, diperkirakan dapat berperan menjadi salah satu sumber infeksi Soil Transmitted Helminth (STH) pada manusia. Hal ini dikarenakan sayuran tidak melalui proses masakmemasak yang juga bertujuan untuk membunuh berbagai mikroorganisme pada makanan karena adanya pengaruh suhu tinggi. Pada beberapa penelitian ditemukan bahwa terdapat prevalensi kontaminasi telur STH sebesar 27,58\% pada kemangi yang dijual di 3 pasar tradisional di Surakarta (Bataha, 2017) dan 39,8\% pada kemangi yang dijual pedagang-pedagang ikan bakar di kota Palu (Widjaja dkk, 2014). Selain lalapan kemangi, juga ditemukan adanya kontaminasi telur STH pada lalapan kubis (Brassica oleracea) yang dijual di sekitar Universitas Lampung memiliki prevalensi sebesar 26,19\% (Wardhana dkk, 2014) dan 13,3\% pada pedagang PKL di Simpang Lima Semarang (Astuti \& Aminah, 2008).

Salah satu faktor yang dapat mempengaruhi terjadinya kontaminasi telur cacing STH pada lalapan antara lain adalah higiene yang buruk. Proses pengolahan kemangi sebelum disajikan menjadi perhatian utama. Umumnya lalapan dicuci terlebih dahulu sebelum disajikan, cara mencuci yang baik adalah dengan dicuci pada air bersih yang mengalir sehingga dapat membersihkan sisa kotoran (Astuti \& Aminah, 2008). Pada penelitian yang dilakukan Suwondo dkk (2015) menjelaskan bahwa kontaminasi telur cacing tambang pada daun kemangi yang dijual di pasar Panam Riau, disebabkan karena pedagang tidak meletakkan kemangi di wadah yang bersih. Higiene pada sayuran sangat berpengaruh terhadap kontaminasi STH. Hal ini diperjelas dengan penelitian oleh Alfiani dkk (2018) menemukan bahwa pada kemangi mentah tanpa pencucian lebih banyak mengandung larva dan telur cacing jika dibanding dengan kemangi yang dilakukan pencucian. Penelitian ini bertujuan untuk menelaah prevalensi dan pengaruh perilaku higiene pedagang kaki lima (PKL) terhadap kontaminasi telur STH pada lalapan kemangi yang dijual di Semarang Barat dan menelaah pengaruh dari proses pencucian sayuran terhadap kontaminasi telur STH pada lalapan kemangi. 
Jurnal Analis Medika Biosains (JAMBS)

Vol.8, No.2, September 2021, pp. 82 - 91

ISSN: 2656-2456 (Online)

ISSN: 2356-4075 (Print)

\section{Metode Penelitian}

Penelitian ini terbagi dalam penelitian deskriptif dan eksperimental. Penelitian deskriptif ini merupakan penelitian cross-sectional untuk mengetahui prevalensi dan pengaruh hygiene PKL terhadap kontaminasi telur STH pada sayur kemangi (O. basilicum L.). Sampel adalah sayur kemangi yang digunakan sebagai sayur lalapan di warung-warung PKL ayam goreng di Kecamatan Semarang Barat, serta untuk menganalisis hubungan factor hygiene pedagang ayam goreng terhadap kontaminasi telur STH. Penelitian dilakukan pada bulan Desember 2019 hingga Februari 2020. Sampel diperoleh dari 40 PKL ayam goreng. Kriteria sampel yang digunakan antara lain: tidak terjatuh di lantai, tidak layu, serta berasal dari pedagang kaki lima di Semarang Barat. Pemeriksaan sampel dilakukan di Labortorium Medis Program Studi DIII Analis Kesehatan Politeknik Katolik Mangunwijaya.

Data pedagang kaki lima (PKL) di Kecamatan Semarang Barat didapatkan melalui Dinas Perdagangan Kota Semarang. Sampel diambil di tujuh Kelurahan di wilayah Kecamatan Semarang Barat, yaitu Kelurahan Bojong Salaman, Kelurahan Cabean, Kelurahan Gisikdrono, Kelurahan Kembangarum, Kelurahan Manyaran, Kelurahan Ngemplak Simongan, Kelurahan Salaman Mloyo. Pelaksanaan penelitian dan survey terhadap PKL sudah mendapatkan persetujuan dari Badan Kesatuan Bangsa dan Politik (BKBP) dengan nomor dokumen 070/45/I/2020. Penelitian diawali dengan wawancara tentang perilaku hygiene pada pedagang kaki lima sebelum dilakukan pengambilan sampel. Perilaku hygiene yang dinilai meliputi: metode pencucian kemangi sebelum dihidangkan, sumber air yang digunakan, dan perilaku cuci tangan pada pedagang. Sampel yang diperoleh kemudian diperiksa dengan menggunakan metode sedimentasi menggunakan larutan $\mathrm{NaCl}$ fisiologis. Analisis data dilakukan secara deskriptif dan statistic melalui uji Regresi Ordinal untuk mengetahui ada tidaknya hubungan perilaku hygiene terhadap kontaminasi telur STH pada lalapam kemangi.

Penelitian eksperimental bertujuan untuk mengetahui pengaruh metode pencucian terhadap kontaminais telur STH pada daun kemangi. Pemeriksaan kontaminasi dilakukan dengan metode flotasi larutan sukrosa 33\%. Penelitian dilakukan dengan teknik simple random sampling. Sampel yang digunakan adalah daun kemangi yang dibeli dari Pasar Karangayu, Semarang Barat. Sebelum diberi perlakuan sampel telah diseleksi sebagai positif terkontaminasi telur STH melalui metode flotasi dan pemeriksaan mikroskopis. Sampel yang sudah terkonfirmasi positif akan mendapat 4 perlakuan: kontrol, pencucian air terendam, pencucian air mengalir, dan pencucian air sabun pencuci sayuran. Jumlah replikasi ditentukan berdasarkan rumus Federer. Perlakuan pencucian air terendam dilakukan dengan merendam seluruh bagian dari 3 gram kemangi kedalam wadah air $300 \mathrm{ml}$. Perlakuan pencucian air mengalir dilakukan dengan mencuci 3 gram kemangi menggunakan air mengalir. Perlakuan pencucian air sabun pencuci sayuran diawali dengan melarutkan sabun dalam air dengan konsentrasi 1:400. Kemangi sebanyak 3 gram kemudian dicuci menggunakan $300 \mathrm{ml}$ larutan sabun dan dibilas dengan air mengalir. Masing-masing kemangi kemudian dihaluskan dengan blender, disaring dengan kertas saring. Air saringan diambil dan dilakukan metode flotasi.

Journal homepage: http://jambs.poltekkes-mataram.ac.id/index.php/home/index 


\section{Hasil Penelitian dan Pembahasan}

Pelaksanaan penelitian diawali dengan melakukan survei jumlah PKL di Kecamatan Semarang Barat di Dinas Perdagangan Kota Semarang. Hasil survei didapatkan data bahwa terdapat 40 PKL di Semarang Barat yang tersebar di 7 kelurahan antara lain: Kelurahan Bojong Salaman, Kelurahan Cabean, Kelurahan Gisikdrono, Kelurahan Kembangarum, Kelurahan Manyaran, Kelurahan Ngemplak Simongan, dan Kelurahan Salaman Mloyo. Sampling dilakukan selama 2 bulan dan disertai dengan pengisian kuisioner dari masingmasing PKL. Pengisian kuisioner dilakukan oleh peneliti melalui metode wawancara dan pengamatan. Sampling yang diambil berupa daun kemangi yang digunakan sebagai lalapan.

Sampel kemangi (Ocimum basilicum L.) diambil menggunakan teknik Purposive Sampling. Sampel kemangi kemudian diperiksa di Laboratorium Medis Program Studi DIII Analis Kesehatan Polteka Mangunwijaya. Hasil pemeriksaan dan kuisioner kemudian diolah dengan uji statistika menggunakan metode Uji Regresi Ordinal untuk mencari ada tidaknya pengaruh perilaku higiene dengan kontaminasi telur cacing Soil Transmitted Helminth (STH).

Tabel 1. Karakteristik Personal Hygiene Responden PKL di Kecamatan Barat

\begin{tabular}{|c|c|c|c|c|}
\hline \multirow[t]{2}{*}{ Variabel } & \multirow{2}{*}{$\begin{array}{c}\mathrm{N} \\
(\%)\end{array}$} & \multicolumn{2}{|c|}{ Kontaminasi } & \multirow[t]{2}{*}{ P value } \\
\hline & & Positif (\%) & Negatif $(\%)$ & \\
\hline \multicolumn{4}{|l|}{ Cara mencuci } & \multirow{4}{*}{0,468} \\
\hline Tidak dicuci & 0 & & & \\
\hline Air mengalir & $20(50)$ & $4(10)$ & $16(40)$ & \\
\hline Dicelup & $20(50)$ & $6(15)$ & $14(35)$ & \\
\hline \multicolumn{4}{|l|}{ Sumber air yang digunakan } & \multirow{4}{*}{0,415} \\
\hline Sumur & $16(40)$ & $4(10)$ & $12(30)$ & \\
\hline PDAM & $22(55)$ & $5(12,5)$ & $17(42,5)$ & \\
\hline Sumur + PDAM & $2(5)$ & $1(2,5)$ & $1(2,5)$ & \\
\hline \multicolumn{4}{|l|}{ Perilaku Cuci Tangan } & \multirow{4}{*}{0,00} \\
\hline Tidak cuci tangan & $28(70)$ & $9(22,5)$ & $19(47,5)$ & \\
\hline Cuci tangan dengan air & $11(27,5)$ & $1(2,5)$ & $10(25)$ & \\
\hline Cuci tangan dengan sabun & $1(2,5)$ & 0 & $1(2,5)$ & \\
\hline
\end{tabular}

Sumber : Data primer 2020

Tabel 1 menunjukkan karakteristik personal hygiene dari responden yang terlibat dalam penelitian. Dari 40 responden yang dikaji, ditemukan bahwa semua pedagang kaki lima melakukan pencucian sayur lalapan kemangi sesaat sebelum disajikan ke konsumen dengan 50\% diantaranya dilakukan dengan pencelupan di ember dan 50\% yang lain dengan air mengalir. Proses pencucian tersebut dilakukan dengan menggunakan air sumur (40\%), air PDAM (55\%), dan kombinasi air sumur dan PDAM (5\%). Hasil kajian juga menemukan bahwa sebanyak 70\% PKL tidak melakukan cuci tangan sesaat sebelum menyajikan lalapan sayur kemangi. Hanya $30 \%$ yang melakukan cuci tangan baik dengan air sabun $(2,5 \%)$ maupun hanya menggunakan air saja $(27,5 \%)$. Kontaminasi telur STH pada perlakuan cuci tangan memiliki skor tertinggi pada perlakuan tidak mencuci tangan sebesar 22,5\%, diikuti oleh cuci tangan dengan air saja (2,5\%), sementara tidak ditemukan adanya kontaminasi pada PKL yang melakukan cuci tangan menggunakan air dan sabun. Pada perilaku cara 


\section{Jurnal Analis Medika Biosains (JAMBS)}

Vol.8, No.2, September 2021, pp. 82 - 91

ISSN: 2656-2456 (Online)

ISSN: 2356-4075 (Print)

pencucian, kemangi yang dicuci dengan cara dicelup memiliki persentase kontaminasi lebih tinggi (15\%) jika

dibandingkan dengan yang dicuci dengan air mengalir (10\%).

Tabel 2. Perbandingan persentase kontaminasi telur cacing pada perlakuan pencucian

\begin{tabular}{lcl}
\hline \multicolumn{1}{c}{ Perlakuan } & Persentase & \multicolumn{1}{c}{ Jenis Telur STH } \\
\hline Pencucian air terendam & $83 \%$ & $\begin{array}{l}\text { Ascaris lumbricoides, cacing tambang, } \\
\text { Trichuris trichiura }\end{array}$ \\
& \multicolumn{2}{l}{ Cacing tambang } \\
\hline Pencucian air mengalir & $50 \%$ & \multicolumn{1}{l}{} \\
\hline Pencucian air sabun pencuci sayuran & $0 \%$ & \\
\hline
\end{tabular}

Tabel 3. Interpretasi hasil perlakuan pencucian

\begin{tabular}{lc}
\hline \multicolumn{1}{c}{ Perbandingan Perlakuan } & Nilai p \\
\hline Pencucian terendam x air mengalir & 0,545 \\
\hline Pencucian air mengalir x sabun pencuci sayuran & 0,182 \\
\hline Pencucian air terendam x sabun pencuci sayuran & 0,015 \\
\hline
\end{tabular}

Pada tabel 2 ditunjukkan bahwa pencucian air mengalir memiliki kemampuan lebih baik dalam menurunkan angka kontaminasi telur STH (50\%) pada kemangi jika dibandingkan dengan pencucian air terendam $(83 \%)$. Selain persentase kontaminasi, pencucian dengan air mengalir juga menghasilkan lebih sedikit jenis kontaminasi daripada pencucian dengan air terendam. Hasil kontaminasi telur nematoda usus pada berbagai macam metode pencucian kemangi (O. basilicum L.) pada kemangi tanpa perlakuan dan perlakuan pencucian air terendam didapatkan berbagai macam spesies telur nematoda usus namun pada perlakuan air mengalir hanya ditemukan spesies hookworm. Tabel 3 menunjukkan bahwa tidak terdapat perbedaan pengaruh perlakuan pencucian terhadap kontaminasi telur cacing STH pada daun kemangi. Perlakuan pencucian dengan air terendam dan air mengalir tidak menunjukkan perbedaan yang signifikan $(\mathrm{p}>0,05)$.

Tidak berpengaruhnya faktor sumber air disebabkan karena baik air sumur dan PDAM tergolong sebagai air bersih, yakni air yang dapat digunakan untuk keperluan sehari-hari dan dapat dikonsumsi/ diminum setelah dimasak (Menkes RI, 1990). Perilaku mencuci tangan berpengaruh terhadap kontaminasi telur cacing Soil Transmitted Helminth (STH) dapat disebabkan oleh karena, rata-rata pedagang tidak menerapkan higiene mencuci tangan yang baik, yaitu menggunakan air mengalir serta sabun. Dari hasil wawancara diketahui bahwa sebagian besar PKL (70\%) tidak mencuci tangan saat akan menyajikan lalapan kemangi. Hal ini dapat menjadi sarana transmisi kontaminasi telur cacing Soil Transmitted Helminth (STH) dari tangan yang kemungkinan terkontaminasi telur cacing Soil Transmitted Helminth (STH) ke lalapan kemangi. Penelitian oleh Umar (2008) menemukan bahwa kebiasaan mencuci tangan menggunakan air dan sabun mempunyai peranan penting dengan pencegahan infeksi kecacingan, dengan mencuci tangan menggunakan air dan sabun lebih efektif dalam menghilangkan kotoran dan telur cacing Soil Transmitted Helminth (STH) yang menempel pada kulit serta kuku pada kedua tangan.

Journal homepage: http://jambs.poltekkes-mataram.ac.id/index.php/home/index 
Kemangi tanpa perlakuan menunjukkan adanya kontaminasi telur Ascaris lumbricoides, Hookworm dan Trichuris trichiura yang disebabkan karena pedagang pasar dalam menjual sayuran dekat dengan tanah dan berdebu karena lokasinya di pinggir jalan raya hal tersebut akan berpotensi menjadi transmisi dari telur nematoda usus. Sayuran yang diletakkan di tempat terbuka berisiko terkontaminasi, telur cacing yang ada di tanah/ debu akan terbawa angin dan menempel pada sayuran (Asihka, 2014). Adanya kontaminasi telur dapat berisiko untuk menularkan infeksi STH pada pembeli saat memilih sayuran yang akan dibeli. Kemangi tanpa perlakuan jika dikonsumsi secara langsung dapat menimbulkan infeksi kecacingan (Harnan dkk, 2019).

Hasil penelitian ini berbeda dengan penelitian-penelitian lain yang menemukan bahwa teknik pencucian memiliki pengaruh terhadap kejadian kontaminasi STH pada lalapan (Alfiani, 2018; Wantini \& Eka, 2019; Mardhiyah dkk, 2019; Tri-Widianingsih dkk, 2019). Tidak adanya perbedaan pengaruh perlakuan pencucian air terendam dan air mengalir dapat disebabkan karena berbagai hal. Tujuan dari pencucian air mengalir yaitu agar telur nematoda usus yang menempel pada kemangi ikut terjatuh saat dicuci dengan air mengalir untuk mengurangi risiko kontaminasi. Tidak berpengaruhnya perlakuan pencucian dengan air mengalir kemungkinan disebabkan karena daun kemangi memiliki permukaan daun yang kasar dan berambut (trikoma) yang kemungkinan menyebabkan telur nematode masih menempel dan tidak ikut mengalir dengan air (WHO, 2012). Meski tidak berbeda secara signifikan, pencucian dengan air mengalir dapat mengurangi jenis kontaminasi telur STH. Keberadaan telur cacing tambang kemungkinan karena disebabkan ukuran telur cacing tambang (60-75 $\mu \mathrm{m})$ lebih kecil jika dibandingkan dengan telur Ascaris lumbricoides (85-95 $\mu \mathrm{m})$, menyebabkan telur cacing tambang lebih mudah tersangkut pada struktur trikoma (rambut) ada daun kemangi. Tujuan dari pencucian air terendam yaitu agar telur nematoda usus yang menempel pada daun kemangi ikut mengapung saat direndam pada air karena berat jenis jenis telur nematoda usus lebih ringan jika dibanding dengan air. Tidak berpengaruhnya perlakuan cuci terendam dapat terjadi karena beberapa faktor di antaranya yaitu faktor penempelan kembali telur nematoda usus yang mengapung pada air disebabkan karena saat pencucian, kemangi dicuci dengan tangan pada baskom yang terendam air maka telur yang mengapung kembali mengikuti pergerakan tangan dan arus air saat mencuci dan menempel pada kemangi (Wantini \& Eka, 2019). Secara mikroskopis pencucian kemangi menggunakan air terendam kurang meminimalisir risiko kontaminasi telur nematoda usus karena rata rata sampel masih terdapat kontaminasi telur dengan jumlah spesies sama dengan control saat diamati dibawah mikroskop.

Penggunaan sabun pencuci sayur menunjukkan efektivitas dapat mengurangi kontaminasi telur STH. Hal ini sesuai dengan penelitian oleh Hajipour et. al. (2020) yang menemukan bahwa penggunaan sabun pencuci sayuran dapat memiliki efektivitas lebih baik dalam menurunkan angka kontaminasi jika dibandingkan dengan pencucian menggunakan air biasa. Hal ini dikarenakan sabun merupakan surfaktan yang bekerja menurunkan tegangan permukaan cairan yang disebabkan oleh sifat ganda molekulnya sebagai polar dan non polar, sehingga dapat mengangkat berbagai kontaminan yang melekat pada kulit, termasuk diantaranya telur cacing (Purnamasari, 2014). 


\section{Kesimpulan}

Kesimpulan dari penelitian ini adalah terdapat prevalensi 25\% lalapan kemangi yang terkontaminasi telur STH pada pedagang kaki lima ayam goreng di Kecamatan Semarang Barat. Kontaminasi telur STH pada daun kemangi dipengaruhi oleh perilaku cuci tangan dari pedagang. Proses pencucian kemangi dengan air terendam dan air mengalir tidak berpengaruh terhadap kontaminasi telur STH. Perlakuan pencucian dengan sabun pencuci sayuran lebih disarankan dikarenakan memiliki efektivitas menurunkan kontaminasi lebih baik jika dibandingkan dengan pencucian dengan air.

\section{Daftar Pustaka}

Alfiani, U. Sulistiyani, Ginandjar, P. 2018. Hubungan Higiene Personal Pedagang dan Sanitasi Makanan Dengan Keberadaan Telur Soil Transmitted Helminths (STH) pada Lalapan Penyetan Di Pujasera Simpanglima Kota Semarang. JKM, 6(1), 685-695

Asihka, V., Nurhayati, Gayatri. 2014. Distribusi Frekuensi Soil Transmitted Helminth pada Sayuran Selada (Lactuca sativa) yang Dijual di Pasar Tradisional dan Pasar Modern di Kota Padang. Vol 3 No3. Jurnal Kesehatan Andalas, 3(3), 480-485

Astuti, R. dan Aminah, S., 2008. Identifikasi Telur Cacing Usus pada Lalapan Daun Kubis yang Dijual Pedagang Kaki Lima di Kawasan Simpang Lima Kota Semarang. Tersedia di : http://jurnal.unimus.ac.id [diakses pada tanggal 20 September 2019].

Bataha, D.W., 2017. Pengaruh Pencucian Terhadap Kontaminasi Telur dan Larva Soil Transmitted Helminth Pada Kemangi (Ocimum basilicum) di Pasar Tradisional Surakarta. [Tugas Akhir]. Surakarta: Universitas Setia Budi

Hajipour, N., Soltani, M., Ketzis, J., Hassanzadeh, P. 2020. Zoonotic Parasitic Organisms on Vegetables: Impact of Production System Characteristics on 2 Presence, Prevalence on Vegetables in Northwestern Iran and Washing Methods for Removal. Food Microbiolgy, 95, 1-33

Harnan, H., Sitorus, R.J., Anwar, C., Hermansyah, H., Hernita. 2020. Hubungan Lalapan dengan Kejadian Infeksi Soil Transmitted Helmiths (STH) pada Anak Sekolah di Kecamatan Gandus Tahun 2019. JAMBS, 7(1), 6-13

Mardhiyah. F.A., Ismawati, Astuti, R.D.I. 2019 Identification of Contamination Ascaris lumbricoides and Trichuris trichiura Egg in The Lettuce (Lactuca sativa) in Food Stalls Around Bandung Islamic University 2018. Prosiding Pendidikan Dokter SPeSIA, 5(1), 249-254

Menteri Kesehatan Republik Indonesia. 1990. Peraturan Menteri Kesehatan No. 416/MENKES/PER/IX/1990 tentang Syarat-syarat dan Pengawasan Kualitas Air. Jakarta: Departemen Kesehatan Republik Indonesia 
ISSN: 2656-2456 (Online) ISSN: 2356-4075 (Print)

Purnamasari, E.N. 2014. Karakteristik Kandungan Linear Alkyl Benzene Sulfonat (LAS) Pada Limbah Cair Laundry. Jurnal Media Teknik, 11(1), 32-36

Suwondo, Elya, F., Lestia, P. 2015. Identifikasi Jenis Telur Nematoda Usus Yang Terdapat Pada Sayuran. Jurnal Biogenesis, 12(1), 14 -18.

Tri-Widianingsih, N.K., Yuliana, E.D., Suardana, A.A.K. 2019. Kontaminasi Soil Trasmitted Helminths pada Helaian Daun dan Cara Pencucian sayuran Kubis di Pasar Tradisisonal. Jurnal Widya Biologi, 1(1), $54-67$

Umar, Z. 2008. Perilaku Cuci Tangan Sebelum Makan dan Kecacingan pada Murid SD di Kabupaten Pesisir Selatan Sumatera Barat. Jurnal Kesehatan Masyarakat Nasional, 2(6), 249-254

WHO. 2012. Folium Ocini Sancti. WHO Monographs on Selected Medicinal Plants Volume2. Available from: http://digicollection.org/hss/en/d/Js4927e/21.html \#Js4927e.21. Diakses tanggal 14 Maret 2020.

Wantini, S. dan Eka, S. 2019. Hubungan Higiene Sanitasi Terhadap Telur Nematoda Usus Pada Lalapan Mentah di Warung Pecel Lele Sepanjang Jalan Z.A Pagar Alam Bandar Lampung. Jurnal Analis Kesehatan, 8(1), 1-6

Wardhana, K.P, Kurniawan, B., Mustofa, S. 2014. Identifikasi Telur Soil Transmitted Helminth Pada Lalapan Kubis (Brassica oleracea) di Warung-Warung Makan Univerrsitas Lampung. Medical Journal of Lampung University, 3(3), 86-95

Widjaja, J., Lobo, L.T., Oktaviani, Puryadi. 2014. Prevalensi dan Jenis Telur Cacing Soil Transmitted Helminth (STH) Pada Sayuran Kemangi Pedagang Ikan Bakar di Kota Palu. J. Buski 5(2), 61-66. 